\title{
Production of Clay-based Ceramic Filter for Water Purification
}

\author{
A. S. Grema, I. M. Idriss, A.N. Alkali, M. M. Ahmed, and H. M. Iyodo
}

\begin{abstract}
The spread of Diseases like Cholera and Diarrhea, which leads to loss of lives in developing countries is commonly caused by use of contaminated water. In this study ceramic pot filters for rural area water purification were developed. The clay sample was tested for physical properties and the mixtures of the clay and sawdust were made in seven (7) proportions of $75 / 25,70 / 30,65 / 35,60 / 40,55 / 45,50 / 50,45 / 55$. The soil tests conducted on the different portions of the clay and sawdust material revealed that the shrinkage of the sawdust blended clay reduced to the minimum of 6.3 compared to the pure clay with 13.7. A fluid dynamic test experiment on each filter was conducted; similarly total dissolved solids (TDS), pH and turbidity tests for both raw water and filtered water were conducted. From fluid dynamic test results, filter 50/50 \% tends to have higher filtration rate compared to the other two filters. From the TDS, pH, and turbidity test,the results obtained show that the filtered water quality has fallen within the world health organization (WHO) standard. It can therefore be concluded that the filtered water is safe for consumption.
\end{abstract}

Keywords - Clay, Sawdust, Filtration, Ceramic filters, Water.

\section{INTRODUCTION}

Clean and safer water is essential in life with many applications, such as cooking and direct consumption. However, its availability is difficult in many communities especially in African rural areas. Rural communities usually depend on streams and wells as sources of water for human consumption. These sources of water are often polluted by run-up chemicals from fertilizers, insecticides, and pesticides from farmlands. The water bodies also get contaminated with micro- organisms during rain showers. In general, it can be said that the world is faced with a major challenge of water contamination in this 21 st century [1]. These materials are relatively expensive for rural dwellers considering their income. Therefore, the need for a cheaper means of treating water for human consumption is of paramount interest. Filtration as a unit operation is mostly used in water treatment. Treatment of contaminated water by filtration process helps in reducing the number of microorganisms in the water, which tends to reduce the spread of diseases among individuals. The use of contaminated water in community leads to spread of diseases like cholera and diarrhea which lead to increase in death rate. From the health sector it is believed that one of the causes of diarrhea comes from consumption of contaminated water. Diarrhea, despite being preventable leads to about 1.8 million deaths on the globe every year [2]. The problem associated with quality of drinking water does not stop at rural communities only because even the urban communities with standard water treatment plants are likely to suffer water borne related disease due to pipes leakage along the supply lines. As such it is important to have a point-of-use means of treating drinking water.

Various means of water treatment have been employed for long. Some materials being used in water treatment include chlorine, activated carbon etc. However, most materials are costly, hardly afforded by low-income earners and eventually the utilization of clay filters emanated in the field of water purification.

Ceramic filtration is a common form of household water treatment in many parts of the world. Ceramic filters are filters made from clay. Several types of both industrially made and locally- produced ceramic filters are currently available in the market and being promoted. The use of ceramic filters in water treatment is increasingly interesting as many researchers reported various studies conducted on its production and usage. Zereffa and Bekalo, [3] produced ceramic filter from kaolin and soft wood. The impurities removal efficiency and microbial activities of the filter was analysed and the best mixing proportions of Kaolin and the sawdust determined. Agbo et al. [4] developed a ceramic filter from clay obtained from Nsu, Enugu and sawdust for water treatment. Puttaiah et al., [5] reported that clay-based filter exhibits enhanced filtration rate compared to the one obtainable from slow sand filters. Subriyer [6] blended clay with fly-ash and produced a filter. The filter was reported to have rejected Iron $(\mathrm{Fe})$ and $\mathrm{Zinc}(\mathrm{Zn})$ in addition to the TDS content of the feed water. Gupta et al. [7] reported E. coli bacteria removal efficiency of more than $99 \%$ using ceramic filter made from mined clay from Raital and Mokalsar near Jodhpur, Rajasthan in India. Clays from different parts of the world have been tested and used for ceramic filter production in water purification applications but no literature was found to report the suitability of Borno clay in this aspect, hence the call for this study. The journal reserves the right to do the final formatting of your paper.
Submitted on October 07, 2021.

Published on December 29, 2021.

A. S. Grema, University of Maiduguri, Maiduguri, Nigeria.

(e-mail: a.grema@ unimaid.edu.ng)

I. M. Idriss, University of Maiduguri, Maiduguri, Nigeria.

(e-mail: iimainakaina@gmail.com)
A. N. Alkali, University of Maiduguri, Maiduguri, Nigeria.

(e-mail: abdulhamidalkali.aa ${ }^{\circledR}$ gmail.com)

M. M. Ahmed, University of Maiduguri, Maiduguri, Nigeria

(e-mail: mmahmed@ unimaid.edu.ng)

M. H. Iyodo, University of Maiduguri, Maiduguri, Nigeria.

(e-mail: mohammedhabu@unimaid.edu.ng) 


\section{MATERIALS AND METHOD}

\section{A. Materials}

The materials used in this study include clay, sawdust, graduated cylinder, polyethylene, $\mathrm{pH}$ meter and turbidity meter, compaction mold, compaction hammer and penetrometer set.

\section{B. Sample Collection}

Clay was collected from Jere local government in Borno State. Fig. 1 shows the location where clay sample was collected. The sawdust was collected from the timber shade in Maiduguri.

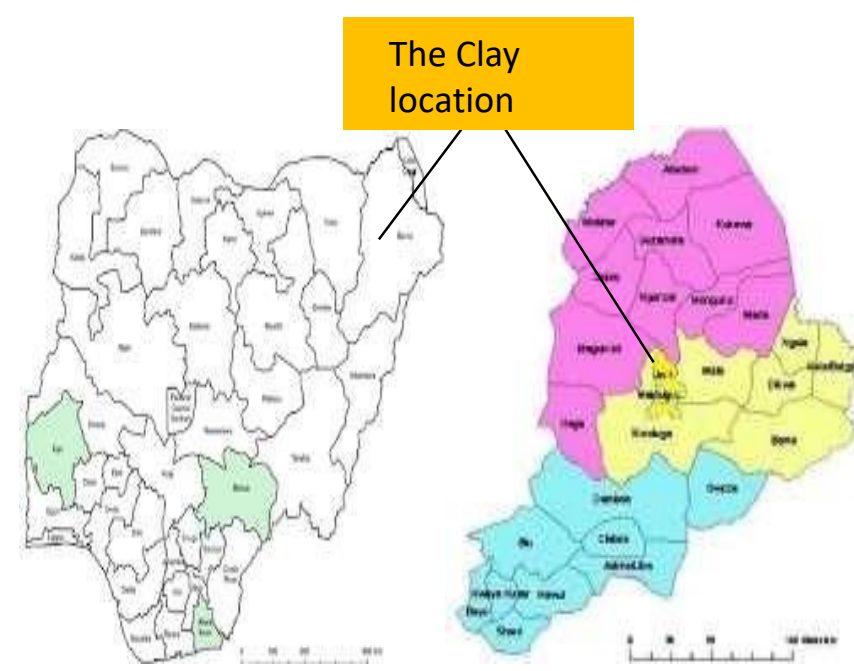

Fig. 1. Location of Jere in Borno State.

Soil Tests: Compaction and Atterberg tests were carried out on the clay and the mixture of clay and sawdust in the following proportions: $75: 25,70: 30,65: 35,60: 40,55: 45$, 50:50 and 45:55, respectively.

Compaction test: The test was conducted to determine the moisture content and dry density of the mixture of clay and the sawdust. The test was carried out in the manner described by Talukdar \& Sharma [8].

Atterberg test: The clay will be used for filter production and in the process of filtration, the level of moisture in the filter will slightly change due to the penetration of the water through the pores of the filter. For this reason, Atterberg test becomes so imperative. The test is used to evaluate the soils consistency in supporting load as their level of moisture changes. In this case the water to be filtered constitutes the load.

The test was carried out to determine the soils' specific gravity and shrinkage limit according to method reported by Niazi et al. [9] while the procedures used by Prakash et al. [10] were adopted to determine plastic limit and liquid limit respectively.

Filter Production: The clay was grinded and mixed with the sawdust in the volume ratios presented in Table I. Water was added to the mixture and molded into a pot-like filter depicted in Fig. 2. It was subsequently allowed to dry after which it was fired in a traditional oven.

\begin{tabular}{l|ccc}
\multicolumn{4}{c}{ TABLE I: VOLUME RATIOS OF CLAY TO SAWDUST } \\
\hline \multirow{2}{*}{ Material } & \multicolumn{4}{c}{ Volume ratio (\%) } \\
\cline { 2 - 4 } & CF 1 & CF 2 & CF 3 \\
\hline Clay & 50 & 65 & 75 \\
Sawdust & 50 & 35 & 25 \\
Total & 100 & 100 & 100 \\
\hline
\end{tabular}

Raw Water Sample: Raw water sample was collected from Maiduguri water treatment. The raw water was tested for various properties which include turbidity, total dissolved solids (TDS) and pH according to method of Shigut et al. [11].

Hydrodynamics Test: The filters were hanged into graduated plastic buckets into which measured amount of water was poured, after which the water started leaking through the pores created by the burnt sawdust. The volumes of water filtered per unit time were recorded appropriately. The experimental setup is depicted in Fig. 2. The filters were labelled as CF 1 for 50:50, CF 2 for $65: 35$ and CF 3 for 75:25, respectively.

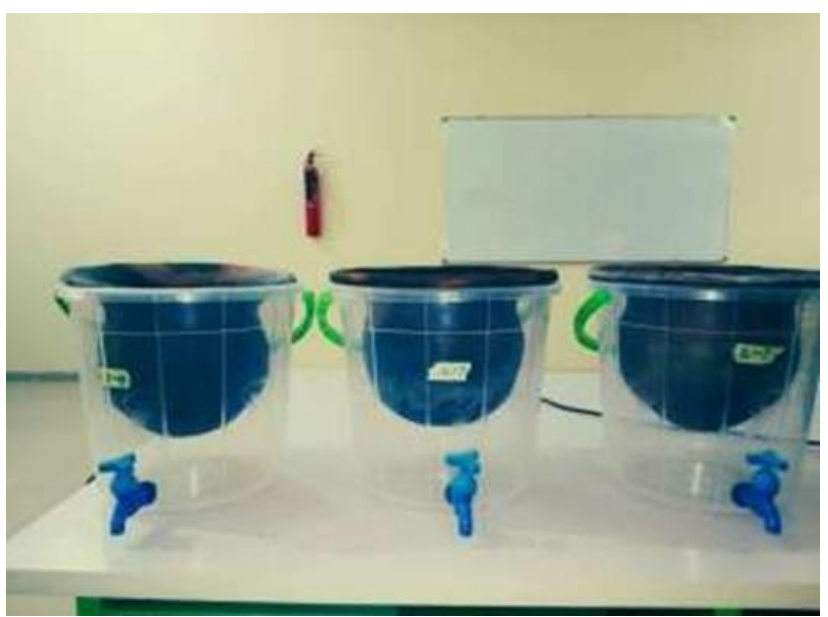

Fig. 2. Filtration setup.

The volume of the filtered water was monitored and recorded at hourly interval in all three buckets during the filtration experiment.

Filtered Water Sample: The filtrates were collected and subjected to various water tests which include turbidity, total dissolved solids (TDS) and $\mathrm{pH}$ in the same manner with raw water sample.

\section{Filter Performance}

The performances of the filters were evaluated to determine how the filters reject impurities. This was carried out using (1) for water qualities.

$$
(q i-q f) \times 100
$$

where $q_{i}$ represents the initial water quality and $q_{f}$ represents filtered water quality respectively.

\section{RESULTS AND DISCUSSION}

\section{A. Clay Characteristics}

Properties of the clay were depicted in Table II. The results show that the sample bears the characteristics of a typical clay 
when compared with literature obtainable from Ombaka [12] and Erdogan [13].

TABLE II: PHYSICAL PROPERTIES OF THE CLAY

\begin{tabular}{cc}
\hline Property & Value \\
\hline Moisture content $(\%)$ & 15.6 \\
Specific gravity & 1.84 \\
Dry density $\left(\mathrm{g} / \mathrm{cm}^{3}\right)$ & 1.80 \\
Plastic limit $(\%)$ & 38.20 \\
Liquid limit $(\%)$ & 37.02 \\
Shrinkage $(\%)$ & 13.70 \\
\hline
\end{tabular}

The compaction test results of the pure clay and that of mixture of the clay and sawdust is presentedin Table III. The maximum dry density was recorded for the pure clay. The dry density tends to decrease with increase in dosage of sawdust. The decrease in the density was because sawdust is lighter than the clay. On the other hand, the gradual increase in the moisture content might have resulted from the moisture content of the sawdust in addition to the water used in making the mixture.

TABLE III: COMPACTION PROPERTIES OF THE CLAY

\begin{tabular}{cccc}
\multicolumn{4}{c}{ TABLE III: COMPACTION PROPERTIES OF THE CLAY } \\
\hline S/N & $\begin{array}{c}\text { Sawdust } \\
\text { dosage }(\%)\end{array}$ & $\begin{array}{c}\text { Moisture } \\
\text { Content }(\%)\end{array}$ & Dry Density $\left(\mathrm{g} / \mathrm{cm}^{3}\right)$ \\
\hline 1 & 0 & 15.6 & 1.8 \\
2 & $75-25$ & 21.7 & 1.64 \\
3 & $70-30$ & 20.5 & 1.7 \\
4 & $65-35$ & 26.4 & 1.5 \\
5 & $60-40$ & 16.9 & 1.5 \\
6 & $55-45$ & 29 & 1.5 \\
7 & $50-50$ & 27.9 & 1.5 \\
8 & $45-55$ & 37 & 1.4 \\
\hline
\end{tabular}

It is notable from the table that the dry density decreases with increase in moisture content. This is because of the reduced compaction to enable the creation of pores in the filter for ease of filtration.

Results of the Atterberg limit tests were presented in Fig. 3 . The specific gravity did not vary significantly but the plastic limit changes irregularly as the liquid limit does.

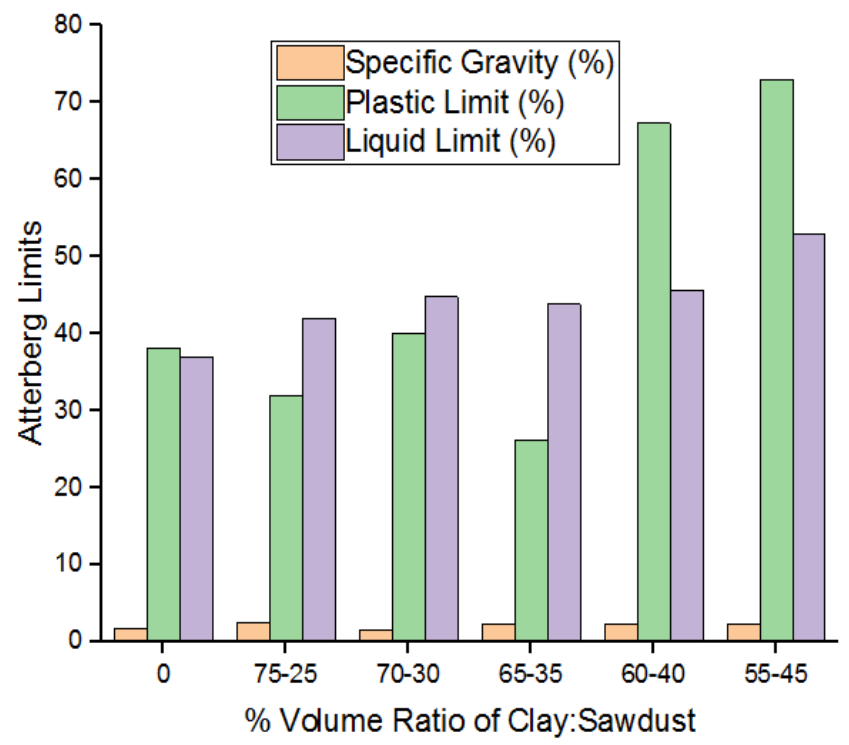

Fig. 3. Atterberg Limits of the Clay.

Clay shrinks during both drying and firing process. It can be seen from the figure that the pure clay has the highest shrinkage limit. This is due to the finest of the clay particles to accommodate morewater, and when eventually dried the clay shrinks.

\section{B. Hydrodynamics}

The flow rate of the water through the pores of the filter vary considerably according to the ratiosof the sawdust in the filter. The higher the sawdust the higher the flow rate. The plot of the flow rate of the filtrate is depicted in Fig. 4. This is in agreement with what is reported by Nnaji et al. [14]. The rate tends to remain steady toward the end in $\mathrm{CF} 3$.

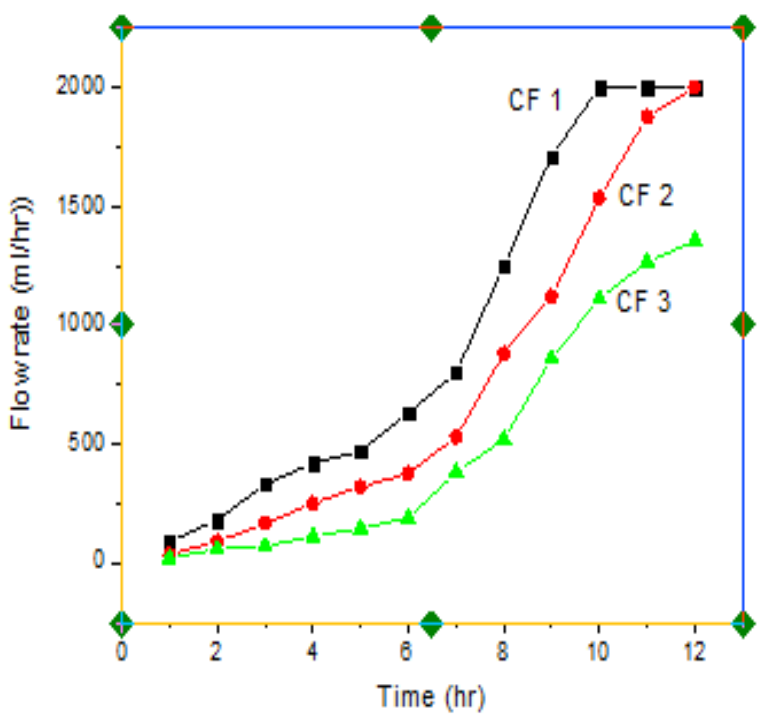

Fig. 4. The Plot of Rate of Filtration.

\section{Water Quality}

The results of the water quality test which comprise of turbidity, TDS and $\mathrm{pH}$ were presented andcompared to that of the raw water and the acceptable standard values for safe drinking water as enshrined in [15] and presented in Table IV.

TABLE IV: COMPARISON RAW AND FILTRATE WATER QUALITY VALUES

\begin{tabular}{cccccc}
\hline & Raw & & & & WHO \\
Water properties & water & CF 1 & CF 2 & CF 3 & 2008 \\
\hline Turbidity (NTU) & 12.32 & 1.33 & 1.16 & 1.02 & $<5$ \\
TDS (ppm) & 91 & 61 & 58 & 55 & $<1200$ \\
$p H$ & 6.8 & 7.66 & 7.4 & 7.61 & $6.5-8$ \\
\hline
\end{tabular}

From Table IV, it can be shown that the turbidity of raw water is well above the threshold limit forsafe drinking water. This can be attributed to the contributory factors of the water source, as manyorganic debris and the likes are washed into the water body by rain. These organic matters when get decayed increases the turbidity. The turbidity of the filtered water decreases with decrease in the percentage of the sawdust in the filter making. This is due to the reduction in the pore size of filters. Comparing the turbidities of the filtered water with that of the threshold limit for safe drinking, the filters demonstrated their capabilities for water purification.

Total dissolved solids in the raw water are not that high as it even falls below the maximum amount allowable for drinking. This indicates that the water source being surface water, has little presenceof salts such as calcium, magnesium, potassium, sodium, bicarbonates, chlorides, and sulfates. It 
can also be as a result of the absence of a discharge from urban sewage and absolutely devoid of industrial wastewater discharge as no industry present along the river. The $\mathrm{pH}$ of the raw water falls in the range of the acceptable values for drinking.

It can be seen that the percentage removal of impurities increases with decrease in sawdust contents of the filters.

\section{CONCLUSION}

Mixtures of clay and sawdust were tested and analyzed for various properties to determine its suitability for water filtration. From these, clay-based filters were produced and tested. Hydrodynamics study was carried out using the synthesized filters of different sawdust/clay contents; subsequently water analyses were conducted on raw and filtered water respectively. From the study it can be deduced that Borno clay is suitable for production of filter for surface water purification. It was also noted that the level of water purification can be enhanced by using small ratio of sawdust to clay in the filter production process. It can as well be understood that the filter is effective against turbidity than in TDS removal.

\section{ACKNOWLEDGMENT}

The authors wish to acknowledge Tertiary Education Trust Fund (TETFund) for financing this research.

\section{REFERENCES}

[1] Sushma D, Richa. Use of Nanoparticles in Water Treatment A review. International Research Journal of Environment Sciences. 2015 October; 4 (10): 103-106.

[2] Rayner J. Current Practices in Manufacturing of Ceramic Pot Filters for Water Treatment. M.Sc. Loughborough University; 2009.

[3] Zeraffa EA, Bekalo TB, Clay Ceramic Filter for Water Treatment. Materials Scienceand Applied Chemistry 2017 May; 34: 69-74. doi: 10.1515/msac-2017-0011.

[4] Agbo SC, Ekpunobi EU, Onu CC, Akpomie KG. Development of Ceramic Filter Candle from NSU (Kaolinite Clay) for Household Water Treatment. International Journal of Multidisciplinary Sciences and Engineering. 2015 January; 6(10): 18-23.

[5] Puttaiah SH, Egumbo H, Madhusudan P, Anil KK, Midhun G. Preparation of Affordable and Multi-functional Clay-based Ceramic Filter Matrix for Treatment of Drinking Water. World Water Congress, pp. 1-8, Mexico, 2017.

[6] Subriyer N. Treatment of Domestic Water Using Ceramic Filter from Natural Clay and Fly-Ash. Journal of Engineering Studies and Research. 2013; 9(3): 71-75.

[7] Gupta S, Satankar RK, Kaurwar A, Aravind U, Sharif M, et al. Household Production of Ceramic Water Filters in Western Rajasthan, India. Engineering, Humanitarian Engineering and Social Entrepreneurship. 2018 May; 13(1): 53-66.

[8] Talukdar P, Sharma B, Determination of Compaction Characteristics of Soil by Static Compaction Method. Proceedings of Indian Geotechnical Conference IGC-pp. 1-9, India, 2014.

[9] Niazi F S, Pinan-Llamas A, Cholewa C, Amstutz C. Liquid limit determination of low to medium plasticity Indiana soils by hard base Casagrande percussion cup vs. BS fall- cone methods. Bulletin of Engineering Geology and the Environment, pp. 1-18, Germany, 2019.

[10] Prakash K, Sridharan A. Use of Uniform and Inert Beads for the Determination of Shrinkage Limit of Fine Grained Soils. Geotech Geol Eng. 2012; 30:1271-1278.

[11] Shigut DA, Liknew G, Irge DD, Ahmad T. Assessment of physicochemical quality of borehole and spring. Appl Water Sci. 2017; 7:155164.

[12] Ombaka O. Characterization and classification of clay minerals for potential applications in Rugi Ward, Kenya. African Journal of
Environmental Science and Technology. 2016 November; 10(11):415431.

[13] Erdogan Y. Physicochemical Properties of Handere Clays and Their Use as a Building Material. Journal of Chemistry. 2015 May; 1-6: doi.org/10.1155/2015/374245.

[14] Nnaji CC, Afangideh BC, Ezeh C. Performance Evaluation of ClaySawdust Composite Filter for Point of Use Water Treatment. Nigerian Journal of Technology. 2016 October; 35(4): 949-956.

[15] WHO, Guidelines for Drinking-water Quality. World Health Organization. WHO Library Cataloguing-in-Publication Data. 2008. 